\title{
Multifocal motor neuropathy
}

INSERM

\section{Source}

INSERM. (1999). Orphanet: an online rare disease and orphan drug data base. Multifocal motor neuropathy. ORPHA:641

Multifocal motor neuropathy ( $\mathrm{MMN}$ ) is a rare acquired immune-mediatedneuropathy characterized clinically by a purely motor deficit with conduction block and asymmetric multifocal weakness, fasciculations, and cramping. 